\title{
BMJ Open Feasibility, acceptability and outcomes at a 12-month follow-up of a novel community-based intervention to prevent type 2 diabetes in adults at high risk: mixed methods pilot study
}

\author{
Linda Penn, ${ }^{1,2}$ Vicky Ryan, ${ }^{1}$ Martin White ${ }^{1,2}$
}

To cite: Penn L, Ryan V, White M. Feasibility, acceptability and outcomes at a 12-month follow-up of a novel community-based intervention to prevent type 2 diabetes in adults at high risk: mixed methods pilot study. BMJ Open 2013;3: e003585. doi:10.1136/ bmjopen-2013-003585

- Prepublication history for this paper is available online. To view these files please visit the journal online (http://dx.doi.org/10.1136/ bmjopen-2013-003585).

Received 11 July 2013 Revised 23 September 2013 Accepted 9 October 2013

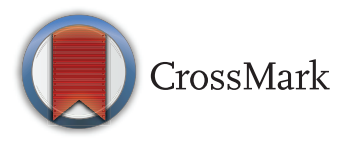

${ }^{1}$ Institute of Health and Society, Newcastle University, Newcastle upon Tyne, UK ${ }^{2}$ Fuse, UKCRC Centre for Translational Research in Public Health

Correspondence to Linda Penn;

linda.penn@ncl.ac.uk

\section{ABSTRACT}

Objectives and design: Lifestyle interventions can prevent type 2 diabetes (T2D) in adults with impaired glucose tolerance. In a mixed methods pilot study, we aimed to assess the feasibility, acceptability and outcomes at a 12-month follow-up of a behavioural intervention for adults at risk of T2D.

Participants: Adults aged 45-65 years with a Finnish Diabetes Risk Score (FINDRISC) $\geq 11$.

Setting: The intervention was delivered in leisure and community settings in a local authority that ranks in the 10 most socioeconomically deprived in England. Intervention: A 10-week supported programme to promote increased physical activity (PA), healthy eating and weight loss was delivered by fitness trainers as twice-weekly group PA or cookery sessions, each followed by behavioural counselling with support to 12 months.

Outcome measures: We assessed feasibility and acceptability of the intervention, and change in behavioural and health-related outcomes at 6 and 12 months.

Results: From 367 registers of interest, 218 participants were recruited to the programme with baseline mean (SD): age 53.6 (6) years, FINDRISC 13.9 (3.1), body mass index $33.5(5.9) \mathrm{kg} / \mathrm{m}^{2}$, waist circumference 108.1 (13.7) $\mathrm{cm}$, PA levels (self-report): daily total 49.1 (5.9) metabolic-equivalent (MET) h/day. Follow-up at 12 months was completed by 134 (61\%) participants, with an estimated mean $(95 \% \mathrm{Cl})$ change from baseline in weight $-5.7(-7.8$ to -2.8$) ;-2.8(-3.8$ to -1.9$) \mathrm{kg}$, waist circumference $-7.2(-9.2$ to -5.2$) ;-6.0(-7.1$ to -5.0 ) $\mathrm{cm}$, and PA level 7.9 (5.8 to 10.1 ); 6.7 (5.2 to 8.2) $\mathrm{MET} h /$ day equivalent, for men and women, respectively (from covariance pattern mixed models). Participants reported an enjoyable, sociable and supportive intervention experience.

Conclusions: Participants' views indicated a high level of intervention acceptability. High retention and positive outcomes at 12 months provide encouraging indications of the feasibility and potential effectiveness of the intervention. A definitive trial of this intervention is warranted.

\section{Strengths and limitations of this study}

- Social marketing and modelling strategies were used to design an engaging intervention.

- The recruitment campaign was successful in reaching the target population, but was time consuming.

- Positioning the intervention in leisure services helped to avoid 'medicalising' type 2 diabetes risk and facilitated the provision of a variety of physical activities with opportunities for maintenance of these postprogramme. This mode of delivery is scalable, but assessment of costeffectiveness is necessary.

- The group-based physical activity and cookery sessions encouraged social support, engagement and positive reinforcement regarding behaviour change.

- More women than men were recruited, although retention in the programme was slightly greater for men than women.

- We identified a need to adapt the programme to attract people from ethnic minority communities.

\section{INTRODUCTION}

Type 2 diabetes (T2D) is an increasingly prevalent chronic disease that is progressive, debilitating and costly to treat. ${ }^{1}$ There is strong evidence from efficacy trials that onset of T2D can be delayed or prevented by lifestyle interventions in adults with impaired glucose tolerance (IGT), ${ }^{2}{ }^{3}$ but translating such interventions to effective, routine delivery remains challenging. Early translational diabetes prevention studies conducted in Finland, Germany and the US assessed weight loss as an intermediate health outcome, thus assuming that weight loss, achieved through these interventions delivered to high-risk individuals, would predict reduced T2D incidence. ${ }^{4}$ More recently, a translational trial delivered to adults at high 
risk in a primary care setting, with a 4.2-year median follow-up and T2D incidence as the primary outcome, demonstrated $36.5 \%$ relative risk reduction $(\mathrm{p}<0.005)$ in T2D incidence in the lifestyle intervention group compared to a usual care control group. ${ }^{5}$ This risk reduction is less than the $57 \%$ risk reduction achieved in some efficacy trials. ${ }^{6}$ The authors of this primary care trial acknowledge the difficulties in translating evidence for effective implementation and suggest that "the feasibility and effectiveness of lifestyle interventions need to be validated within the population in which they are intended to be used."

The UK National Institute for Health and Care Excellence (NICE) guidance for preventing T2D in high-risk individuals identified evidence gaps relating to risk identification of those suitable for lifestyle-change programmes and the need for translation of research evidence to UK practice. ${ }^{3}$ A report commissioned by NICE highlighted the increased prevalence of T2D in low socioeconomic status groups and acknowledged that engaging people from these groups in preventive interventions is challenging. ${ }^{7}$

Translational T2D prevention studies have generally used classroom-based behavioural counselling ${ }^{4} 8$ and this approach is advocated in the development and implementation of a European Guideline and Training Standard for Diabetes Prevention (IMAGE) guidelines. ${ }^{9}{ }^{10}$ Similarly, the Good Ageing in Lahti region (GOAL) before-and-after implementation study for T2D prevention used a structured counselling programme that drew on social cognitive and self-regulation theories of behaviour change. ${ }^{11}$ However, the Finnish Diabetes Prevention Study (DPS) ${ }^{12}$ and American Diabetes Prevention Programme (DPP) ${ }^{13}$ trials (which provided efficacy evidence for T2D prevention) both included group delivered physical activity (PA) sessions. Experiential learning theory emphasises the central role that a 'here-and-now' concrete experience, along with observation and reflection, plays in promoting subsequent higher order purposeful action. ${ }^{14}$ In this experiential approach, performing an action in a specific instance and considering its effects is precedent to generalisation. $^{15}$ We therefore developed an alternative approach to intervention delivery that included group delivered PA sessions to provide immediate experience of different exercise activities, facilitate peer interaction and accommodate different learning styles. ${ }^{16}$ We have drawn on experiential learning theory as well as behaviour change theories and techniques in intervention development. ${ }^{17-19}$

We report on the feasibility, acceptability and behavioural and health-related outcomes at a 12 month follow-up of a novel community-based intervention called 'New life, New you' (NLNY), directed at adults at risk of T2D. NLNY was novel in its delivery via supported group PA and cookery sessions, each followed by reflection, advice and counselling. ${ }^{20} 21$

In England, health improvement responsibilities are assigned to local government (from April 2013). Thus,
NLNY, which was designed as a health and leisure service partnership to be delivered by local authority employed fitness trainers, offers a model with strong potential for future public health commissioning and service delivery. Feasibility and acceptability of this novel intervention were assessed in preparation for a definitive effectiveness trial.

\section{METHODS}

\section{Objectives}

We aimed to assess the feasibility, acceptability and likely effectiveness of the intervention to change PA, weight and other health-related outcomes at 12 months of follow-up.

\section{Study design, participants and data collection}

We used mixed methods to assess process and outcomes at 6 and 12 months of follow-up, ${ }^{22}$ using an uncontrolled before-and-after study design, with embedded qualitative interviews.

Two participant cohorts were recruited between March 2009 and November 2010, the first supported by social marketing campaigns and the second by word of mouth or 'signposted' from primary care. Inclusion criteria were: age 45-65 years, living in central Middlesbrough UK, and with elevated risk of T2D. Individualised 10 year risk of T2D was determined at baseline using the Finnish Diabetes Risk Score (FINDRISC), a prospective risk assessment tool that uses simple, non-invasive measures, including height, weight and waist circumference, as well as questions about family history and lifestyle. ${ }^{23}$ To give an indication of socioeconomic status, we used home post codes to assign the English Index of Multiple Deprivation (IMD), an ecological, composite measure based on routinely available data in seven categories of deprivation (income, employment, health and disability, education skills and training, barriers to housing and other services, crime and living environment) at the Lower Super Output Area (LSOA: a small administrative area with a population of about 1500) level to each participant. ${ }^{24}$ Previous diagnoses of T2D or inability to participate in moderate PA were exclusion criteria. Details of the target population, and recruitment strategies have been reported previously. ${ }^{20}{ }^{21}$ Participants completed the standard local authority leisure services questionnaire, which included questions regarding medication, diagnosed medical conditions and any other condition that might prevent people from participating in PA. The leisure services standard protocol for reporting injury or other adverse side effects was used. Following a brief screening (self-report of: age, area of domicile and history of T2D), potential participants were invited to attend an individual assessment that was conducted by one of the NLNY health and fitness trainers in a convenient community location. The consultation incorporated motivational interviewing techniques to promote engagement in the intervention. ${ }^{25}$ After their baseline assessment, those with FINDRISC 11-20 who wished to 
participate were allocated to the intervention programme. Those with FINDRISC $>20$ were advised to see their general practitioner (GP) and were able to join the programme with their GP's permission (providing there was no diagnosis of T2D). The trainers conducted further assessments at 6 and 12 months in one-to-one consultations.

To assess intervention feasibility and acceptability, we recorded recruitment and retention through the programme and follow-up. We conducted qualitative interviews with participants at 6 and 12 months of postprogramme. The interview topic guide was developed from our previous research in this area. ${ }^{26}$ Interviewees were purposively selected for success in PA increase at 6 or 12 months of follow-up. Interviews were recorded and transcribed verbatim. As part of the qualitative evaluation, we sought to elicit participants' views on acceptability of the intervention and research procedures. Participant perspectives of their behaviour changes are reported separately. $^{21}$

\section{Outcome measurements}

To evaluate likely effectiveness, the primary outcome measures were change in PA levels and variety. These were assessed through a self-report instrument that we developed from the PA diary used in the Newcastle arm of the European Diabetes Prevention Study (EDIPS-Newcastle) randomised controlled trial. ${ }^{27}$ We calculated the daily total PA level in metabolic-equivalent tasks for each hour (MET h) from a $24 \mathrm{~h}$ recall, recorded in half-hour periods of activity level (eg, lying down=1, standing $=3$, brisk walking $=5$, strenuous activities $=8) .{ }^{28}$ The amount and variety of leisure time PA over level 5 was recorded as a recall of type of activity and number of sessions of each activity of at least $15 \mathrm{~min}$ duration over the previous week. Secondary outcomes were change in weight and waist measurements and FINDRISC. ${ }^{23}$ Dietary assessment was based on questions about specific foods (number of portions of fruit and vegetables consumed daily, and type of bread, milk and fat usually consumed), and was aligned with the dietary advice given to participants. All measures were assessed at each time point.

\section{Intervention development}

Intervention design built on research evidence for T2D prevention including the Finnish DPS $^{12}$ and EDIPSNewcastle. ${ }^{26} 27$ The intervention was developed in accordance with the UK National Social Marketing Centre benchmark criteria, ${ }^{29}$ designed for adults living in socioeconomically disadvantaged areas, and intended to be delivered in leisure and community settings. ${ }^{20} 21$ Market segmentation identified target groups as middle-aged and older men and women on low incomes. ${ }^{30}$ Consultations with stakeholders (potential participants and experienced local fitness trainers) informed creative work with the delivery staff to develop the intervention design, name, logo and project documents, all of which were refined in usability testing. ${ }^{31}$

\section{Intervention}

NLNY trainers delivered a 10-week programme of twiceweekly $1.5 \mathrm{~h}$ sessions to groups of 15-20 participants. Participant preferences, for example for a single-sex activity group or for particular PAs, were accommodated where possible. Each NLNY session comprised a supervised PA or, on two or three occasions within each 10-week programme, a cookery session, followed by a reflective discussion that covered PA, nutrition, weight management and strategies for behaviour change. Monthly NLNY newsletters with information, advice and recipes were available to participants, mostly online. PAs centred on the interests of each participant group, with flexibility to repeat popular activities. Sessions were leisure centre based, but also included trainer-led walks. The supported cookery sessions were designed to encourage healthy eating and to demonstrate the ease with which healthy food could be prepared. Nutritional information incorporated the importance of reading food labels with advice based on the Eat-well plate, ${ }^{32}$ including reduction in fat and increase in fibre intake, in line with the DPS protocol and NICE guidance. $^{3}{ }^{12}$ Weight reduction was advised for those overweight, who were the majority. The trainers introduced behaviour change strategies (including goal setting, action planning, barrier identification, social support, selfmonitoring, advance planning for relapse prevention and contingent rewards), as the need arose, with regular repetition during the supported sessions. ${ }^{18}$

At the end of the 10-week programme, participants who had completed $\geq 80 \%$ attendance received an 'access to leisure' card that enabled free leisure service use for 12 months. After the programme, ongoing support with regular mobile phone text message and email reminders, 'drop-in' activity sessions and encouragement to join in local events such as organised walks and runs continued up to the assessment at 12 months of follow-up. The full intervention manual is available from the corresponding author.

\section{Data analysis}

We analysed outcome data using SPSS (IBM SPSS Inc, V.17) and SAS/STAT, V.9.2 software. ${ }^{33}$ For this feasibility study, analyses of the data collected were mainly descriptive. For repeated measures analysis of continuous outcome variables, we used covariance pattern mixed models which allow appropriate estimation of the mean change (and associated SE) between visits, allowing for missing observations over time. ${ }^{34}$ We estimated (with 95\% CIs) mean change from baseline to 6 and 12 months for PA level, weight, waist circumference and FINDRISC data for those participants who started the 10-week programme. From the available self-report data, we report the number and percentage of those who participated in different activities in the previous week and the number and percentage of different foods consumed within food groups at each time point for those who completed 12 months in the study. 
We analysed transcribed data, from the interview study, using the framework approach. ${ }^{35}$ A priori themes explicit in the topic guide were extended with themes emerging from the data. NVivo software was used to arrange the data. Detailed qualitative analysis, based on the theoretical domains framework, is reported separately. ${ }^{19}{ }^{36}$ For the analysis reported here, key themes relating to acceptability were extracted along with illustrative quotes.

\section{RESULTS}

From 271 registers of interest for the first cohort 166 (61\%), participants were recruited to the programme, including $56(26 \%)$ recruited via word of mouth. From 96 registers of interest for the second cohort, 52 (54\%) participants were recruited, including 44 (85\%) recruited via word of mouth. In total, there were 367 registers of interest and the trainers recruited $218(59 \%)$ participants to the programme. Just over half $(53 \%)$ of the NLNY participants lived in an LSOA within the lowest quintile of deprivation based on 2010 IMD ranks for all England. A total of $134(61 \%)$ programme group participants completed follow-up at 12 months. More women than men were recruited, although this difference was less in the second cohort, and a slightly higher proportion of men than women completed the 12-month follow-up. A flow chart of progress through the NLNY programme to 12 months of follow-up is detailed in figure 1.

Baseline data (continuous variables) for all those recruited to the programme and for male and female participants separately are shown in table 1 and distributions across key categories of these variables are shown in table 2. A total of $194(89 \%)$ participants were recorded as overweight or obese, of which $64(29 \%)$ were severely obese (body mass index, BMI $>35 \mathrm{~kg} / \mathrm{m}^{2}$ ). Of the men recruited, $61(91 \%)$ recorded a waist circumference $>91 \mathrm{~cm} ; 126(83 \%)$ of women recorded a waist circumference $>83 \mathrm{~cm}$. Participants reported taking part in PA at a level of $>5$ MET $\mathrm{h} /$ day for only $1 \mathrm{~h} /$ day on average with one activity being the median number of PA types. The trainers recruited 21 participants with baseline FINDRISC $<11$, all of whom were overweight and inactive, into the programme. The question, "Do you smoke currently?" was answered by 125 (57\%) participants, of whom 3 men and 3 women reported currently smoking. The question, "Have you ever smoked?" was answered by $140(64 \%)$ participants, of whom 20 men and 44 women reported smoking at some time previously.

Baseline values for key variables were mostly similar for those who completed 12 months of follow-up and for those who left the study early. However, participants who dropped out of the programme by 10 weeks or left before 6 or 12 months of follow-up came from significantly more deprived areas than those who completed these follow-up assessments, as shown in table 3.
Changes in key variables are shown in table 4 . The results suggest overall increases in PA levels (total and leisure time), an increase in the variety of $\mathrm{PA}$ and decreases in the BMI, weight, waist circumference and FINDRISC. Changes were greater in the first 6 months of follow-up than in the period from 7 to 12 months. Nevertheless, beneficial changes in all outcomes occurred between 0 and 12 months with estimated mean (95\% CI) change from baseline in weight -5.7 ( -7.8 to $-2.8) ;-2.8(-3.8$ to -1.9$) \mathrm{kg}$, waist circumference -7.2 ( -9.2 to -5.2$)$; -6.0 ( -7.1 to -5.0$) \mathrm{cm}$ and PA level 7.9 (5.8 to 10.1); 6.7 (5.2 to 8.2) MET h/day equivalent for men and women, respectively.

Table 5 shows the change in numbers $(\%)$ participating in specific leisure time activities at baseline, 6 and 12 months. Participation in gym-based activities, sports and 'other' activities (ie, any activities not otherwise specified, including the popular aqua-fit sessions) showed substantial increases over time.

Table 6 shows changes in numbers (\%) consuming categories of specific foods at baseline, 6 and 12 months. There were notable increases in consumption of brown bread, soft margarine and five or more portions of fruit and vegetables/day, and decreases in consumption of white bread, butter and hard margarine.

Table 7 shows key themes and associated quotations relating to acceptability of the intervention, derived from the qualitative interviews. The intervention delivery environment was viewed as welcoming, friendly, sociable, enjoyable, comfortable and convenient. The only negative comment was about the potential for disruptive elements within groups, although this comment was balanced by an appreciation of the trainers' efforts to contain this. Participants had high praise for the trainers and would recommend the programme to others.

\section{DISCUSSION}

\section{Statement of principal findings}

Most participants came from areas of social deprivation, reflecting the target population, and fewer men than women were recruited. High retention and further recruitment by word-of-mouth recommendation, along with positive comments in the qualitative interviews, suggest high levels of acceptability of the intervention. Positive outcomes at 12 months, including increased PA, weight loss, reduction in waist circumference and FINDRISC, and increase in the consumption of fruit and vegetables, are encouraging indications of the likely effectiveness of the intervention. Intervention delivery, by fitness trainers in leisure and community settings incorporating robust outcome data collection for monitoring purposes, provides a viable model for service provision in the UK.

Almost all NLNY participants were overweight or obese at baseline, with elevated risk of developing T2D. Just over half $(53 \%)$ of the participants were living in areas located in the lowest, and $65 \%$ in the lowest two, 


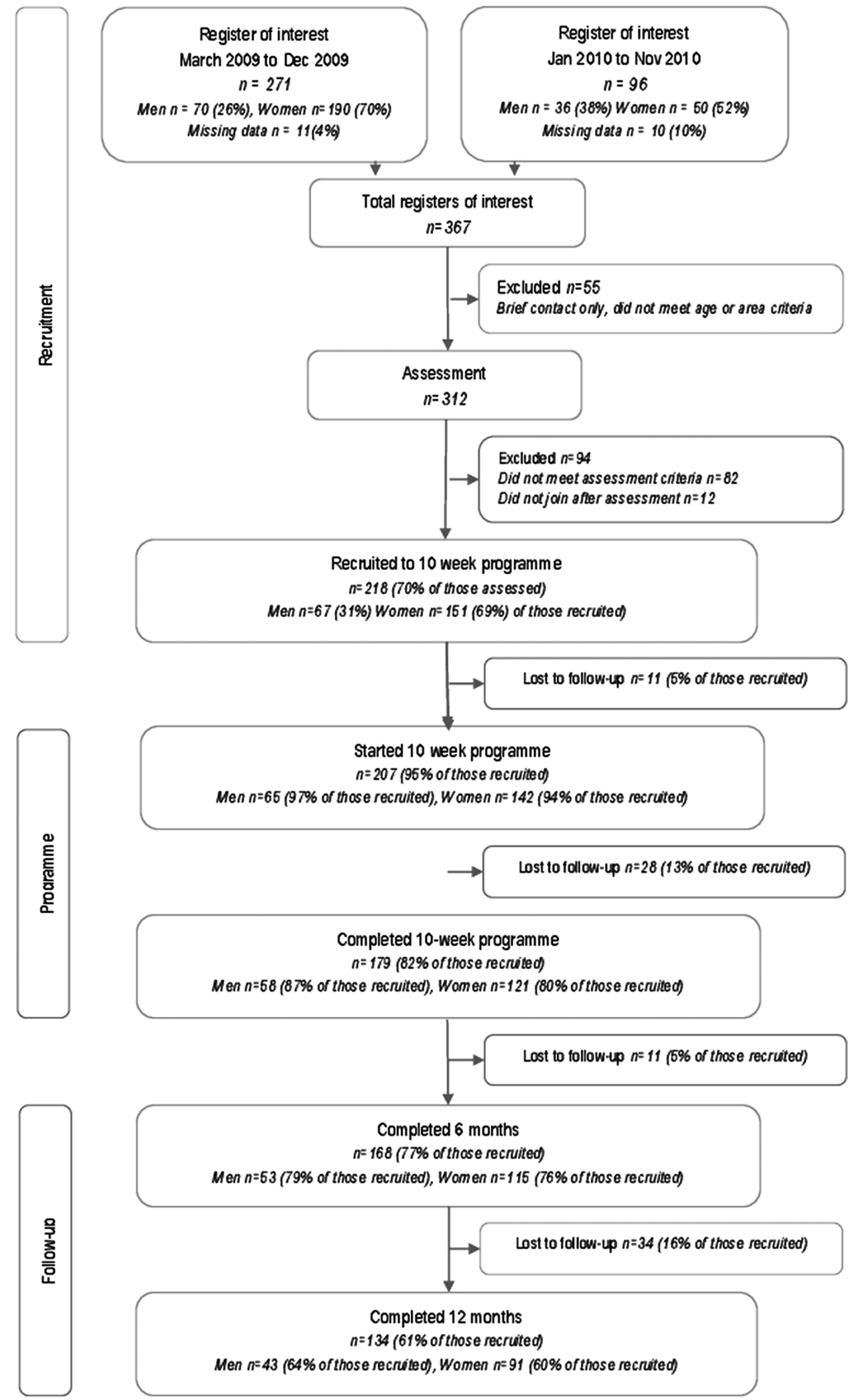

Figure 1 Flow chart of recruitment and progress through the 'New life, New You' pilot evaluation.

quintiles of deprivation based on 2010 IMD ranks for all England. Recruitment and retention of people from this population in a preventive intervention is challenging and the retention rate of $61 \%$ at 12 months, with many participants recruited by word of mouth, demonstrates intervention acceptability. Mean beneficial change was demonstrated in measures of PA and in objective measures of weight and waist circumference, resulting in 
Table 1 Mean (SD) for continuous baseline variables of 'New life, New You' participants, $\mathrm{n}=218$ (men=67, women=151)

\begin{tabular}{llccccc}
\hline Variable & $\mathbf{n}$ & All participants & $\mathbf{n}$ & Men & $\mathbf{n}$ & Women \\
\hline FINDRISC & 204 & $13.9(3.1)$ & 63 & $14.1(3.4)$ & 141 & $13.9(2.9)$ \\
Age (years) & 213 & $53.6(6.0)$ & 67 & $51.3(5.2)$ & 146 & $54.7(6.1)$ \\
IMD score & 207 & $40.0(21.6)$ & 66 & $45.5(20.3)$ & 141 & $37.4(21.8)$ \\
BMI (kg/m $\left.{ }^{2}\right)$ & 199 & $33.5(5.9)$ & 64 & $34.6(6.0)$ & 135 & $33.0(5.8)$ \\
Weight (kg) & 202 & $92.1(19.8)$ & 65 & $105.5(20.6)$ & 137 & $85.7(15.9)$ \\
Waist (cm) & 189 & $108.1(13.7)$ & 61 & $116.4(14.8)$ & 128 & $104.2(10.9)$ \\
Physical activity: total (MET h/day) & 193 & $49.1(5.9)$ & 61 & $48.4(6.3)$ & 132 & $49.5(5.8)$ \\
\hline
\end{tabular}

BMI, body mass index; FINDRISC, Finnish Diabetes Risk Score; IMD, Index of Multiple Deprivation; MET, metabolic-equivalent.

reduction in FINDRISC for many participants. The main areas of PA increase were gym-based and sports activities (including badminton) as well as popular 'aqua-fit' sessions (which were provided separately for men and women). Walking, hobbies and swimming activities were fairly consistent across the study time period, which suggests that the new activities were additions rather than replacements.

The dietary assessment was limited by resources and a perceived need to minimise respondent burden. Of interest was the increase in reported portions of fruit and vegetables consumed per day. There were only modest beneficial changes in other food groups. Refinement of dietary advice to promote wholemeal (rather than brown) bread and skimmed (rather than semiskimmed) milk should be considered.

\section{Strengths and limitations of the study}

Recruitment and retention

Intervention development was strengthened by drawing on social marketing (profiling a target population, pretesting intervention design through stakeholder consultations and positioning in community settings) and modelling (using behavioural and intermediate health outcomes) strategies to ensure an appropriate, engaging and pragmatic intervention. ${ }^{31} 37$ The promotional campaign, led by the fitness trainers, was time consuming and 'signposting' from the National Health Services (NHS) Health Checks programme within primary care might be a more efficient long-term option for recruitment. ${ }^{38}$ However, we cannot be sure whether this different recruitment strategy would affect retention and outcomes.

More women than men were recruited, in common with previous diabetes prevention studies, ${ }^{12}{ }^{13}$ and this remains a concern, especially in view of the greater prevalence of T2D in men. ${ }^{39}$ Our social marketing approach to intervention development led us to provide single-sex PA classes. However, further gender-sensitive strategies need to be developed to attract men to participate in T2D prevention interventions. ${ }^{40}$

Themes from the interview study suggest a high degree of acceptability. However, these interviews were conducted with participants who remained in the study and may not reflect the perspectives of those who dropped out. Those who left the study early tended not to respond to contacts. Participants were recruited from the community and although the early recruitment strategy involved advertising the programme, later participants were mainly recruited through word of mouth. We suggest that as later recruits only became interested in this opportunity through those already participating,

Table 2 Numbers (\%) in each category of baseline variable for 'New life, New You' participants

\begin{tabular}{|c|c|c|c|c|c|c|}
\hline \multirow{2}{*}{$\frac{\text { Variable }}{\text { FINDRISC }}$} & \multicolumn{5}{|c|}{ Number (\%) in categories } & \multirow[t]{2}{*}{$\begin{array}{l}\text { Missing } \\
\text { data }\end{array}$} \\
\hline & $7-11$ & $12-14$ & $15-20$ & $>20$ & & \\
\hline & $49(23)$ & $73(34)$ & $75(34)$ & $7(3)$ & & $14(6)$ \\
\hline \multirow[t]{2}{*}{ Age groups (years) } & $<49$ & $50-54$ & $55-59$ & $60-65$ & & \\
\hline & $77(35)$ & $50(23)$ & $48(22)$ & $38(17)$ & & $5(2)$ \\
\hline \multirow[t]{2}{*}{ IMD rank (All England quintiles) } & 5 & 4 & 3 & 2 & 1 & \\
\hline & $4(2)$ & $19(9)$ & $43(20)$ & $25(12)$ & $116(53)$ & $11(5)$ \\
\hline \multirow[t]{2}{*}{ BMI categories $\left(\mathrm{kg} / \mathrm{m}^{2}\right)$} & $18.5-25$ & $25-29$ & $30-34$ & $35-39$ & $\geq 40$ & \\
\hline & $5(2)$ & $51(23)$ & $79(36)$ & $38(17)$ & $26(12)$ & $19(9)$ \\
\hline \multirow[t]{2}{*}{ Waist IDEA* categories men $(\mathrm{cm})$} & $<84$ & $84-91$ & $92-98$ & $99-106$ & $\geq 107$ & \\
\hline & 0 & 0 & $3(5)$ & $19(28)$ & $39(58)$ & $6(9)$ \\
\hline \multirow[t]{2}{*}{ Waist IDEA* categories women $(\mathrm{cm})$} & $<76$ & $76-83$ & $84-91$ & $92-101$ & $\geq 102$ & \\
\hline & 0 & $2(1)$ & $12(8)$ & $44(29)$ & $70(46)$ & $23(15)$ \\
\hline
\end{tabular}


Table 3 Mean (SD) for key baseline variables by retention/attrition at each follow-up stage

\begin{tabular}{|c|c|c|c|c|c|c|c|}
\hline Variable & $\begin{array}{l}\text { Numbers } \\
\text { available for } \\
\text { variable at } \\
\text { baseline (from } \\
n=218 \text { recruited) }\end{array}$ & $\begin{array}{l}\text { Completed at } \\
10 \text { weeks } \\
(n=179)\end{array}$ & $\begin{array}{l}\text { Withdrew } \\
\text { at } 10 \text { weeks } \\
(n=39)\end{array}$ & $\begin{array}{l}\text { Completed at } \\
6 \text { months } \\
(n=168)\end{array}$ & $\begin{array}{l}\text { Withdrew } \\
\text { at } 6 \text { months } \\
(n=50)\end{array}$ & $\begin{array}{l}\text { Completed at } \\
12 \text { months } \\
(n=134)\end{array}$ & $\begin{array}{l}\text { Withdrew } \\
\text { at } 12 \text { months } \\
(n=84)\end{array}$ \\
\hline FINDRISC & 204 & $14.1(3.2)$ & $13.2(2.3)$ & $14.1(3.2)$ & $13.4(2.4)$ & $14.1(3.5)$ & $13.7(2.4)$ \\
\hline Age (years) & 213 & $53.9(6.1)$ & $52.0(5.7)$ & $54.1(6.0)$ & $51.9(6.5)$ & $54.3(6.1)$ & $52.2(5.9)$ \\
\hline IMD score* & 207 & $38.0(21.3)$ & $49.7(20.5)$ & $38.0(21.3)$ & $47.0(22.0)$ & $36.8(21.3)$ & $45.7(21.0)$ \\
\hline BMI $\left(\mathrm{kg} / \mathrm{m}^{2}\right)$ & 199 & $33.7(6.0)$ & $32.1(4.4)$ & 33.7 (6.2) & $33.3(5.3)$ & $33.6(6.2)$ & $33.3(5.2)$ \\
\hline Weight (kg) & 202 & $92.5(19.9)$ & 88.7 (18.5) & $92.5(20.2)$ & $90.0(17.6)$ & $92.0(20.3)$ & $92.4(18.9)$ \\
\hline Waist (cm) & 189 & $108.3(13.5)$ & $106.4(14.4)$ & 108.2 (13.6) & $108.0(13.6)$ & $108.1(13.8)$ & $108.3(12.9)$ \\
\hline $\begin{array}{l}\text { PA: Total } \\
\text { (MET h/day) }\end{array}$ & 193 & $49.1(6.1)$ & $49.2(4.8)$ & $48.9(5.9)$ & $50.2(6.2)$ & $49.2(6.1)$ & $48.9(5.6)$ \\
\hline $\begin{array}{l}\text { PA: Leisure } \\
\text { (h/week) }\end{array}$ & 179 & $1.1(.08)$ & $1.3(0.7)$ & $1.1(0.8)$ & $1.4(0.9)$ & $1.1(0.8)$ & $1.3(0.9)$ \\
\hline
\end{tabular}

they were not a population subfraction with prior interest in supervised PA training.

We did not exclude ethnic minorities from taking part in the programme, but as only two people from these groups became involved we identified this as a design limitation, considering the potentially raised prevalence of T2D within the UK South Asian and African communities. ${ }^{3}$ We are currently developing an adaptation of the programme, ${ }^{41}$ specifically to target local ethnic minority communities, which also includes provision for younger age participants from these groups in line with NICE guidance. ${ }^{3}$ This adaptation will be similarly assessed for feasibility, acceptability and outcomes at 12 months.

Recruitment to this study relied on a self-reported FINDRISC. ${ }^{23}$ We agreed on some flexibility for inclusion in this feasibility study because the FINDRISC algorithm includes a heavily weighted family history question and validity is compromised where data on family history are unavailable. Family history in risk score assessment introduces bias (eg, for people from single-parent families or people with younger than average parents), ${ }^{42}$ which might have importance for this socioeconomically disadvantaged participant population. Seven of those recruited to NLNY who did not report family history at baseline did so at 6 months, and we know that some of this difference was due to new T2D diagnoses in family members. The participants with baseline FINDRISC $<11$ were all overweight and inactive. ${ }^{23}$ However, this flexibility in recruitment introduces a design limitation and highlights the difficulty that the trainers experienced in 'turning away' people who were keen to participate in the programme. This difficulty was an important finding from the feasibility evaluation and an alternative strategy will be needed for a definitive trial. A risk score and confirmatory blood test, as advised in NICE guidance, would ensure more precise inclusion criteria. In this context, point of care glycated haemoglobin (HbA1c) may be convenient. HbA1C cut-points to identify highrisk individuals are recommended in NICE guidance, but these do not identify a population with IGT and the appropriate $\mathrm{HbAlc}$ cut-points for the purpose of preventive interventions are untested. ${ }^{3}$

\section{Data administration}

In this pilot study, we asked the fitness trainers to undertake risk assessment and collect all data. This strategy was designed to reflect the likely future practice, with inbuilt potential for robust monitoring and quality assurance measures for service provision. However, data collection involved new procedures for the fitness trainers and some baseline data were not recorded. We have subsequently improved the data administration procedures. However, in a definitive trial, trial data collection will need to be independent of intervention delivery.

Respondent burden was a key consideration for this participant group and the data collection procedures were designed to minimise this. Nevertheless, the dietary assessment method was weak. We have subsequently used the Dietary Instrument for Nutrition Education (DINE) questionnaire as advised by the National Obesity Observatory for weight management interventions. ${ }^{43}$ In a definitive trial, the need for a more robust, objective measurement of PA and better dietary assessment will need to be balanced against increased respondent burden.

\section{Intervention delivery and capacity}

The intervention design was strengthened by the incorporation of individual and group-based delivery. The one-to-one risk assessment consultations provided opportunities to introduce topics that facilitated motivational interviewing. ${ }^{23}$ The group-based PA and cookery sessions encouraged social support with mutual encouragement. Group-based sessions are likely to reduce cost and 


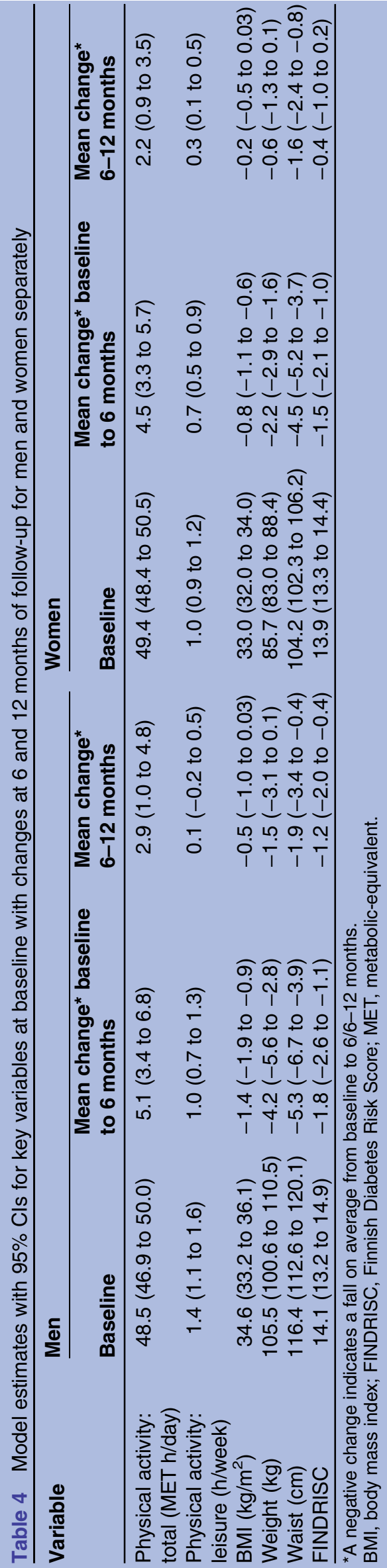

Table 5 Number (\%) of participants engaging in each leisure time physical activity (with level greater than 5 MET $h$ equivalent) in the previous week

\begin{tabular}{|c|c|c|c|}
\hline & \multicolumn{3}{|c|}{ Participation in activity } \\
\hline & Baseline & 6 months & 12 months \\
\hline Walking & $116(66)$ & $117(66)$ & $111(63)$ \\
\hline Hobbiest & $63(36)$ & $30(17)$ & $48(27)$ \\
\hline Dancing & $7(4)$ & $10(6)$ & $11(6)$ \\
\hline Gym based $\ddagger$ & $10(6)$ & $115(65)$ & $79(45)$ \\
\hline Swimming & $13(10)$ & 32 (18) & $23(13)$ \\
\hline Sport§ & & $21(12)$ & 22 (12) \\
\hline Others ${ }^{* *}$ & $23(13)$ & $85(48)$ & $74(42)$ \\
\hline \multicolumn{4}{|c|}{$\begin{array}{l}\text { *Participants who completed the follow-up at } 12 \text { months ( } n=134 \text { ) } \\
\text { with data at all three time points } n=110 \text {. } \\
\text { †Hobbies comprised: car maintenance, gardening and } \\
\text { do-it-yourself. } \\
\text { †Gym based included: a variety of locally available leisure centre } \\
\text { classes and individual gym equipment use. } \\
\S \text { Sport comprised: athletic track use and badminton court use. } \\
{ }^{*} \text { Others referred to any activity not otherwise specifically } \\
\text { allocated (including popular aqua-fit classes). }\end{array}$} \\
\hline
\end{tabular}

Table 6 Number (\%) of participants eating specific categories of food at baseline, 6 and 12 months of follow-up*

\begin{tabular}{|c|c|c|c|}
\hline Food category & Baseline & 6 months & 12 months \\
\hline \multicolumn{4}{|l|}{ Milk } \\
\hline Skimmed & $16(17)$ & $23(24)$ & $21(21)$ \\
\hline Semi-skimmed & $73(76)$ & $69(70)$ & $72(74)$ \\
\hline Full cream & $3(3)$ & $1(1)$ & $1(1)$ \\
\hline None & $4(4)$ & $5(5)$ & $4(4)$ \\
\hline Item missing & $2(2)$ & - & - \\
\hline \multicolumn{4}{|l|}{ Bread } \\
\hline Wholemeal & $39(40)$ & $43(44)$ & $39(40)$ \\
\hline Brown & $22(22)$ & $30(31)$ & $42(43)$ \\
\hline White & $29(30)$ & $16(16$ & $9(9)$ \\
\hline None & $3(3)$ & $3(3)$ & $6(6)$ \\
\hline Item missing & $5(5)$ & $6(6)$ & $6(6)$ \\
\hline \multicolumn{4}{|l|}{ Spread } \\
\hline Low fat/sterol & $18(18)$ & $21(21)$ & $22(22)$ \\
\hline Soft margarine & $30(31)$ & $35(36)$ & $36(37)$ \\
\hline $\begin{array}{l}\text { Butter/hard } \\
\text { margarine }\end{array}$ & $42(43)$ & $28(29)$ & $24(25)$ \\
\hline None & $7(7)$ & $13(13)$ & $16(16)$ \\
\hline Item missing & $1(1)$ & $1(1)$ & - \\
\hline \multicolumn{4}{|l|}{ Fat (cooking) } \\
\hline Spray oil & $20(20)$ & $21(21)$ & $16(16)$ \\
\hline Oil & $63(64)$ & $67(68)$ & $69(70)$ \\
\hline Hard fat/lard & $1(1)$ & $2(2)$ & $0(0)$ \\
\hline None & $13(13)$ & $7(7)$ & $12(12)$ \\
\hline Item missing & $1(1)$ & $1(1)$ & $1(1)$ \\
\hline \multicolumn{4}{|c|}{ Portions/day of fruit and vegetables } \\
\hline$\leq 2$ & $23(24)$ & $5(5)$ & $3(3)$ \\
\hline $3-4$ & $40(41)$ & $37(38)$ & $44(45)$ \\
\hline$\geq 5$ & $29(30)$ & $56(57)$ & $51(52)$ \\
\hline Item missing & $6(6)$ & - & - \\
\hline
\end{tabular}


Table 7 Acceptability of the New Life New You intervention: key themes from participant interviews and illustrative quotes

\section{Welcoming}

Friendly, sociable, enjoyable, supportive

Comfortable, convenient

Well-paced, varied activities

Trainers (rapport)

Recommendable
I was absorbed in from walking through the door (Participant M, male, age 48)

I was shown round and I realised I wasn't the only one [overweight]. [There is] a

cross-section of people who actually use a gym (Participant K, male, age 63)

We're always chatting and welcoming, very welcoming (Participant B, female, age 45)

Everybody was really friendly (Participant F, male, age 50)

You're looking for a kind of, not friendship but ... people association (Participant I, female, age 60)

You're meeting different people the different sessions you go to (Participant A, female, age 59)

I do enjoy the group, so that was an incentive in itself (Participant $\mathrm{C}$, female, age 58)

It was one of the best things I have ever done. I thoroughly enjoyed it (Participant $G$, female, age 57)

It is mixing with the people who are actually applying to this as well (Participant $\mathrm{H}$, female, age 54)

She watches me because I am frightened of the water you see even though I go to Aqua fit; I'm frightened of the water so she tends to stay with me (Participant G, female, age 57) It felt very comfortable to come (Participant $F$, male, age 50)

[Men are] a lot shyer than women to join such a group. Just men was a big thing, all shapes and sizes joined (Participant E, male, age 50)

The leisure centre opens early, so I can go swimming before work (Participant C, female, age 58)

You are under no pressure (Participant M, male, age 48)

The more familiar you get with it [gym routine] the more confident you get (Participant $\mathrm{K}$ male, age 63)

The first activity was a walk and I did find that hard, but [I thought] I need to find out what else there is so I carried on. I am glad I did push on (Participant G, female, age 57)

One of the good things about it is the level of choice (Participant $\mathrm{J}$, female, age 59) They gave you so much encouragement along the way. They are a fantastic team (Participant I, female, age 60). The commitment that they give is unbelievable (Participant E, male, age 50)

They listen to what I have to say (Participant D, female, age 53)

Also, they are quite innovative (Participant $A$, female, age 59)

I didn't know any of them [trainers] before I came in and at the end of the first session it was as though I had known them for quite a long time (Participant $\mathrm{M}$, male, age 48) If they see someone that's taking the Mick, they'll pull them to one side (Participant F, male, age 50)

l've been raving on about it ever since to everybody (Participant 0 , female, age 47) The way I would put it to somebody is, 'Just come and it's an enjoyable experience' (Participant M, male, age 48)

I met a lady who was already doing it. She said, 'I think it's great: go for it' (Participant J, female, age 59)

Recommend? [I would] absolutely, totally and utterly (Participant F, male, age 50) potentially improve the cost-effectiveness of the intervention. ${ }^{44}$ Positioning the intervention within leisure services helped to avoid 'medicalising' the problem and enabled a variety of PAs to be provided. The trainers were accessible to the participants on a casual basis, both during the 10-week programme and after its completion, as they were regularly present in the leisure centres with other groups. The trainers encouraged participants to make independent use of leisure centre facilities and join mainstream activity classes. New mainstream classes were introduced in response to the requirements of NLNY participants, some of whom invested in their own access to leisure service cards after completing follow-up at 12 months. The local leisure centre continued to provide a meeting point for participants post follow-up. The standard (Register of Exercise Professionals) training programmes for fitness trainers provided a good foundation for intervention delivery, which we enhanced with extra training in motivational interviewing and good clinical practice. Similar delivery capacity would be available in other areas of the UK by utilising staff trained to deliver fitness programmes, such as within local authority leisure services.

\section{Intervention cost}

In this study, we focused on developing an engaging intervention and sustainable administration procedures. Group sessions were used to maximise efficiency. 
Funding provision was appropriate for a developmental project and further cost savings are being explored in refining the service model. Economic evaluation of the NLNY service model will be undertaken as part of a definitive trial.

\section{Sample size}

This feasibility study has provided data that will inform sample size estimation for a definitive trial and show how the NLNY intervention performs in comparison to interventions used in previous trials: for example, in NLNY, $21 \%$ of participants lost $\geq 5 \%$ of their body weight at 12 months of follow-up; the equivalent value in EDIPS was $38 \% .^{6}$ A comparison of reductions in the waist circumference will also be informative. ${ }^{45} 46$

\section{Strengths and weaknesses in relation to other studies}

In planning the NLNY intervention, we were able to draw on the experience of EDIPS-Newcastle as previously described. ${ }^{27}$ The efficacy evidence for lifestyle, diet and PA interventions to prevent T2D has been tested in research settings. ${ }^{3}$ Although it is difficult to compare across studies with different participant gender distributions and baseline levels for the outcome variables of interest, it appears that weight loss observed at 12 months in this pilot study (mean $5.7 \mathrm{~kg}$ men, $2.8 \mathrm{~kg}$ women and $4.3 \mathrm{~kg}$ overall) was comparable to that achieved in the Finnish DPS (mean $4.2 \mathrm{~kg}$ ) and more than in EDIPS-Newcastle (mean $2.3 \mathrm{~kg}$ ). Similarly, it appears that the reduction in waist circumference (mean $7.2 \mathrm{~cm}$ men, $6 \mathrm{~cm}$ women and $6.6 \mathrm{~cm}$ overall) was more than in the Finnish DPS (mean $4.4 \mathrm{~cm}$ ) and EDIPS-Newcastle (mean $1.7 \mathrm{~cm}){ }^{12}{ }^{27}$ In the International Day for the Evaluation of Abdominal Obesity (IDEA) study, waist circumference was shown to be a better predictor than BMI of diabetes and cardiovascular disease. ${ }^{46}$

Some countries have already implemented large-scale diabetes prevention programmes for high-risk groups. Finnish national diabetes prevention program (FIN-D2D) and GOAL were both conducted in Finland, ${ }^{47-49}$ and a state-wide primary prevention programme has been implemented in Saxony in Germany. ${ }^{8}$ The Australian 'Life!' Study in Victoria State was developed with a direct recruitment strategy, underpinned by social marketing and developed from the Greater Green Triangle Translational study ${ }^{50}{ }^{51}$ These programmes did not achieve the same degree of weight change as the DPP and DPS. The DPP and DPS included supervised group PA sessions within their protocols, but service provision models have relied mainly on classroom-based counselling. ${ }^{8}$ The alternative approach used here may be more effective, especially for hard-to-reach groups. Provision of the 12 month free access to leisure card increased the cost of the intervention and this may make the NLNY intervention inefficient or difficult to afford. The commissioners are considering alternatives such as subsidised service access for continued implementation.

Recruitment in previous diabetes prevention trials has relied on assessment of IGT using an oral glucose tolerance test. This is not practical for service provision ${ }^{3}$ and large-scale prevention programmes have used risk scoring methods. ${ }^{52}$ Blood testing is required to exclude undiagnosed T2D, but was not included in the NLNY pilot. Addressing this limitation will be important prior to a definitive trial. The most convenient procedure would be a risk score screening together with a simple blood test (such as point of care HbAlc followed by venous blood testing for those with high risk to exclude T2D) ${ }^{5}$

\section{Importance of the study: possible mechanisms and} implications for clinicians or policymakers

The NLNY feasibility study has demonstrated successful recruitment and retention, the feasibility of collecting individual level outcome data within a service model, and likely effectiveness to change behavioural and intermediate health outcomes.

The NHS Health Checks programme in England offers simple tests including BMI and, where appropriate, $\mathrm{HbAlc}$ to adults aged between 40 and 74 years. ${ }^{38}$ NICE guidance advocates lifestyle intervention for T2D prevention linked to NHS Health Checks. ${ }^{3}$ Delivery capacity is a major consideration in planning service provision for diabetes prevention. By citing the NLNY intervention within local authority leisure services, we have utilised appropriate and available facilities together with the expertise of existing trained staff. This study demonstrates the feasibility of an intervention model, delivered by fitness trainers in leisure and community settings with collection of robust outcome data. This model has potential for scalable service provision.

\section{Future research}

The outcome data reported here are encouraging and the next step is a formal test of effectiveness and costeffectiveness in a definitive trial prior to translation for mainstream practice. The results of a qualitative process evaluation of participants' perspectives of their behavioural change ${ }^{53}$ provide further evidence to complement the findings reported here on feasibility, acceptability and potential effectiveness.

\section{CONCLUSION}

High retention and positive outcomes at 12 months are encouraging indications of the potential success of the NLNY intervention. A controlled trial with assessment of cost-effectiveness is warranted. The intervention provides a potential model for sustainable service provision in the UK and is scalable.

Acknowledgements The authors would like to thank the participants and all the staff who helped with the study. The study was funded by a consortium including Sport England; Middlesbrough Primary Care Trust; Public Health North East; and Middlesbrough Council. The authors wish to thank Diabetes 
UK for their input to the Steering Group. In 2012, London hosted the Olympic and Paralympic Games. The aspiration that the Games would encourage greater participation in physical activity inspired the development of the 'New life, New You' (NLNY) intervention for T2D prevention as a health and sports sector partnership and the project was awarded the 2012 'Inspire' mark. We acknowledge the contribution made by local organisations in planning this intervention in connection with the Olympic and Paralympic legacy.

Contributors MW was a member of the Steering Group responsible for securing funding and for the outline plan for the NLNY intervention and evaluation. LP contributed to the development of the NLNY pilot intervention, designed the pilot evaluation and the qualitative study, and conducted the qualitative interviews. VR conducted the statistical analyses. MW and VR reviewed and contributed to the manuscript drafted by LP. All authors read and agreed on the final version.

Funding Middlesbrough Council; Middlesbrough Primary Care Trust; Public Health North East, Sport England. Newcastle University, Institute of Health and Society provided funding for open access publication.

Competing interests The business case and outline plan for this pilot study was determined by a steering committee. This included representatives from members of the organisations that comprised the funding consortium as well as the Principal Investigator for the evaluation, co-author MW. The detailed development of the intervention was then progressed by a small operational team including the evaluation researcher, co-author LP. The operational team reported to the steering committee. The funders had no role in the collection, analysis and interpretation of data, writing of the article or in the decision to submit it for publication. MW, VR, and LP receive salaries from Newcastle University, Institute of Health and Society that provides open access funding for the publication.

Ethics approval Newcastle University Ethics Committee.

Provenance and peer review Not commissioned; externally peer reviewed.

Data sharing statement No additional data are available.

Open Access This is an Open Access article distributed in accordance with the Creative Commons Attribution Non Commercial (CC BY-NC 3.0) license, which permits others to distribute, remix, adapt, build upon this work noncommercially, and license their derivative works on different terms, provided the original work is properly cited and the use is non-commercial. See: http:// creativecommons.org/licenses/by-nc/3.0/

\section{REFERENCES}

1. International Diabetes Federation. Diabetes atlas. Brussels: International Diabetes Federation, 2006

2. Gillies CL, Abrams KR, Lambert PC, et al. Pharmacological and lifestyle interventions to prevent or delay type 2 diabetes in people with impaired glucose tolerance: systematic review and meta-analysis. BMJ 2007;334:299.

3. NICE. PH 38 Preventing type 2 diabetes-risk identification and interventions for individuals at high risk. http://guidanceniceorguk/ PH38 2012. http://guidance.nice.org.uk/PH38 (accessed 26 Jul 2012).

4. Johnson M, Jones R, Freeman C, et al. Prevention of type 2 diabetes: reviewing mechanisms of successful interventions and translation of major trial evidence to practice. 2011. http:// wwwniceorguk/guidance/indexjsp?action=download\&o=57044. http:// www.nice.org.uk/guidance/index.jsp?action $=$ download $\& 0=57044$

5. Costa B, Barrio F, Cabré JJ, et al. Delaying progression to type 2 diabetes among high-risk Spanish individuals is feasible in real-life primary healthcare settings using intensive lifestyle intervention. Diabetologia 2012;55:1319-28

6. Penn L, White M, Lindström J, et al. Importance of weight loss maintenance and risk prediction in the prevention of type 2 diabetes: analysis of European diabetes prevention study RCT. PLOS ONE 2013;8:e57143.

7. Taylor J. A pragmatic review of risk identification and interventions to prevent type 2 diabetes in high risk adults in disadvantaged and vulnerable groups. NICE PH38: Preventing type 2 diabetes-risk identification and interventions for individuals at high risk. London, 2011.
8. Schwarz PEH, Schwarz J, et al. Development of a diabetes prevention management program for clinical practice. Public Health Rep 2007;122:258-63.

9. Lindstrom J, Neumann A, Sheppard KE, et al. Take action to prevent diabetes - the IMAGE toolkit for the prevention of type 2 diabetes in Europe. Horm Metab Res 2010;42(Suppl 1):S37-55

10. Greaves C, Sheppard K, Abraham C, et al. Systematic review of reviews of intervention components associated with increased effectiveness in dietary and physical activity interventions. BMC Public Health 2011;11:119.

11. Absetz $P$, Valve R, Oldenburg B, et al. Type 2 diabetes prevention in the 'Real World'. Diabetes Care 2007;30:2465-70

12. Tuomilehto J, Lindstrom J, Eriksson JG, et al. Prevention of type 2 diabetes mellitus by changes in lifestyle among subjects with impaired glucose tolerance. N Engl J Med 2001;344:1343-50.

13. Knowler WC, Barrett-Connor E, Fowler SE, et al. Reduction in the incidence of type 2 diabetes with lifestyle intervention or metformin. N Engl J Med 2002;346:393-403.

14. Kolb DA. Experiential learning: experience as the source of learning and development Englewood Cliffs. Prentice-Hall, 1984.

15. Keeton MT. Experiential learning: rationale, characteristics and assessment. San Francisco, CA USA: Jossey-Bass Inc., 1976.

16. Checkley $\mathrm{K}$. The first seven....and the eighth a conversation with Howard Gardner. Educ Leadersh 1997;55:8-13.

17. Dombrowski SU, Avenell A, Sniehott FF. Behavioural interventions for obese adults with additional risk factors for morbidity: systematic review of effects on behaviour, weight and disease risk factors. Obes Facts 2010;3:377-96.

18. Michie S, Ashford S, Sniehotta FF, et al. A refined taxonomy of behaviour change techniques to help people change their physical activity and healthy eating behaviours: the CALO-RE taxonomy. Psychol Health 2011;26:1479-98

19. Michie S, Johnston M, Abraham C, et al. Making psychological theory useful for implementing evidence based practice: a consensus approach. Qual Saf Health Care 2005;14:26-33.

20. Penn L, Lordon J, Lowry $\mathrm{R}$, et al. Translating research evidence to service provision for prevention of type 2 diabetes:development and early outcomes of the 'New life, New you' intervention. $\mathrm{Br} J$ Diabetes Vasc Dis 2011:11:175-81.

21. Penn L, Lordon J, Lowry R, et al. Towards the translation of research evidence to service provision: experience from North East England, UK. In: Schwarz PEH, Reddy P, Greaves C, Dunbar J, Schwarz J, eds. Diabetes prevention in practice. Dresden: WCPD, 2010:189-95.

22. Moffatt S, White M, Mackintosh J, et al. Using quantitative and qualitative methods in health services research. What happens when mixed method findings conflict? [isrctn61522618]. BMC Health Serv Res 2006;6:28.

23. Lindstrom J, Tuomilehto J. The diabetes risk score: a practical tool to predict type 2 diabetes risk. Diabetes Care 2003;26:725-31.

24. The Area Based Analysis Unit Understanding patterns of deprivation. Office for National Statistics, Regional trends. London, UK: Office for National Statistics, 2009.

25. Rollnick S, Mason P, Butler C. Health behaviour change. Edinburgh: Churchill Livingstone, 1999.

26. Penn L, Moffatt S, White M. Participants' perspective on maintaining behaviour change: a qualitative study within the European Diabetes Prevention Study. BMC Public Health 2008;8:235.

27. Penn L, White M, Oldroyd J, et al. Prevention of type 2 diabetes in adults with impaired glucose tolerance: the European Diabetes Prevention RCT in Newcastle upon Tyne, UK. BMC Public Health 2009;9:342-1.

28. Ainsworth BE, Haskell WL, Whitt MC, et al. Compendium of physical activities: an update of activity codes and MET intensities. Med SCi Sports Exerc 2000;32(9 Suppl):S498-516.

29. National Social Marketing Centre. Social marketing National Benchmark Criteria. 2008 (accessed Aug 2008)

30. Sport England. Active People Survey 1. Active People 2007.

31. Hastings G. Social marketing: why should the devil have all the best tunes? Oxford: Elsevier Ltd, 2007.

32. Food Standards Agency. Your guide to the eatwell plate. London: Department of Health, 2011.

33. SAS/STAT software, Version 9.2 of the SAS System for Windows (SAS software, Version 9.2 for Windows. Copyright (C) 2002-2008, SAS Institute Inc., Cary, NC, USA [program]

34. Brown HK, Prescott RP. Applied mixed models in medicine. Chichester: John Wiley, 1999.

35. Ritchie J, Lewis J. eds. Qualitative research practice: a guide for social science students and researchers. London: Sage Publications, 2003.

36. Penn L, Dombrowski SU, Sniehotta FF, et al. Participants' perspectives on making and maintaining behaviour changes in a 
lifestyle intervention for type 2 diabetes prevention: qualitative study using the theory domain framework. BMJ Open 2013;3:e002949.

37. MRC (Medical Research Council UK). Developing and evaluating complex interventions: new guidance. 2008; http://www.mrc.ac.uk/ Utilities/Documentrecord/index.htm?d=MRC004871. http://www.mrc. ac.uk/complexinterventionsguidance

38. Department of Health NHS Health Check Programme. Putting Prevention First NHS Health Check: Vascular Risk Assessment and Management Best Practice Guidance. 2009.

39. Moody A. Diabetes and hyperglycaemia. In: Health Survey for England $2011 \mathrm{H}$, social care and lifestyles, ed. London: NHS The Health and Social Care Information Centre, 2012

40. Smith JA, Robertson S. Men's health promotion: a new frontier in Australia and the UK? Health Promot Int 2008;23:283-9

41. Liu JJ, Davidson E, Bhopal RS, et al. Adapting health promotion interventions to meet the needs of ethnic minority groups: mixed methods evidence synthesis. Health Technol Assess 2012;16:1-469.

42. Katz I, Corlyon J, La Placa V, et al. The relationship between parenting and poverty. Joseph Rowntree Foundation, 2007.

43. Richardson D, Cavill N, Ells L, et al. Measuring diet and physical activity in weight management interventions: a briefing paper. National Obesity Observatory, 2011.

44. Gillett M, Chilcott J, Goyder L, et al. Prevention of type 2 diabetes: risk identification and interventions for individuals at high risk. Economic Review and Modelling: NICE Centre for Public Health Excellence ScHARR: School of Health and Related Research, University of Shefield, 2012.

45. Ashwell M, Gunn P, Gibson S. Waist-to-height ratio is a better screening tool than waist circumference and BMI for adult cardiometabolic risk factors: systematic review and meta-analysis. Obes Rev 2012;13:275-86.
46. Balkau B, Deanfield JE, Després J-P, et al. International Day for the Evaluation of Abdominal Obesity (IDEA): A study of waist circumference, cardiovascular disease, and diabetes mellitus in 168 000 primary care patients in 63 countries. Circulation 2007;116:1942-51

47. Saaristo T, Peltonen M, Keinänen-Kiukaanniemi S, et al. National type 2 diabetes prevention programme in Finland: FIN-D2D. Int $J$ Circumpolar Health 2007;66:101-12.

48. Absetz P, Oldenburg B, Hankonen N, et al. Type 2 diabetes prevention in the real world. Diabetes Care 2009;32:1418-20

49. Kujala UM, Jokelainen $\mathrm{J}$, Oksa $\mathrm{H}$, et al. Increase in physical activity and cardiometabolic risk profile change during lifestyle intervention in primary healthcare: 1-year follow-up study among individuals at high risk for type 2 diabetes. BMJ Open 2011;1:e000292

50. Laatikainen T, Dunbar JA, Chapman A, et al. Prevention of type 2 diabetes by lifestyle intervention in an Australian primary health care setting: Greater Green Triangle (GGT) Diabetes Prevention Project. BMC Public Health 2007;19:249.

51. Dunbar J, Colagiuri S, Reddy P, et al. Scaling up type 2 diabetes prevention programs: national and state interventions in Australia. In Schwarz P, Reddy P, Greaves C, et al., eds. Diabetes prevention in practice. Dresden: WCPD, 2010:45-55.

52. Schwarz PEH, Gruhl U, Bornstein SR, et al. The European Perspective on Diabetes Prevention: development and Implementation of a European Guideline and training standards for diabetes prevention (IMAGE). Diab Vasc Dis Res 2007;4:353-57.

53. Penn L, Dombrowski SU, Sniehotta FF, et al. Participants' perspectives on making and maintaining behavioural changes in a lifestyle intervention for type 2 diabetes prevention: a qualitative study using the theory domain framework. BMJ Open 2013;3:pii: e002949 